\title{
EL CONCEPTO DE EDUCACIÓN EN LA FILOSOFÍA DE LEONARDO POLO: «AYUDAR A CRECER» ${ }^{1}$
}

\author{
THE CONCEPT OF EDUCATION IN \\ LEONARDO POLO'S PHILOSOPHY: \\ «HELPING TO GROW»
}

doi: $10.21555 /$ rpp.v33i33.2400

Joaquín León-Parodi

Universidad de Navarra, España

jleonp@unav.es

https://orcid.org/0000-0003-2698-3511

Recibido: septiembre 29, 2021 - Aceptado: noviembre 16, 2021

\section{RESUMEN}

La Antropología trascendental de Leonardo Polo (España, 1926-2013) puede ser un aporte sustancial para la fundamentación de la «Educación», por lo que es pertinente ampliar su estudio, aplicándolo a la filosofía de la educación. La antropología poliana distingue, en el hombre, una triple dimensión: a) naturaleza humana, compuesta por el cuerpo y el alma -con sus facultades de inteligencia y voluntad- en estado natural; b) esencia del hombre, que consiste en las perfecciones adquiridas en la naturaleza -hábitos de la inteligencia y virtudes de la voluntad- desde el acto de ser, por medio del hábito innato de la sindéresis (el yo moderno), y c) acto de ser personal, conformado por la coexistencia libre, el conocer y amar personales. Polo, tratando cuestiones de filosofía de la educación, define el quehacer educativo como «ayudar a crecer», noción que adquiere del pedagogo español Tomás Alvira (España, 19061992). En este trabajo, mediante una revisión bibliográfica de la obra antropológica poliana, se profundiza en este concepto, concluyéndose que la educación se debe desarrollar desde la persona, ya que así cada hombre -único e irrepetible-, con la orientación y ayuda de sus educadores, podrá cumplir su misión íntima, y podrá también crecer de manera irrestricta en hábitos de la inteligencia y las virtudes de la voluntad, matizándolos según él «es» y está llamado a «ser».

Palabras claves: antropología de la educación, antropología trascendental, educación, familia, Leonardo Polo, filosofía de la educación.

1 El autor de este artículo agradece al Gobierno de Navarra por el patrocinio en la realización de la tesis doctoral -de la que emana esta investigación-, por medio de la «Beca de Ayudas Predoctorales para la realización de Programas de Doctorado de Interés para Navarra». 


\begin{abstract}
Leonardo Polo's Transcendental Anthropology could be a substantial contribution to the foundation of «Education», that's why it is pertinent to broaden its study and use it in the philosophy of education. Polo's anthropology distinguishes in man a triple dimension: a) the human nature, composed of the body and the soul -with its faculties of intelligence and will- in a natural state; $b$ ) the human essence, consisting of the perfections acquired in nature -habits of the intelligence and virtues of the will- from the act of being through the innate habit of synderesis (the modern self); c) the personal act of being, composed by free coexistence, personal knowing and personal loving. Approaching issues of philosophy of education, Polo defines the educational task as «helping to grow», a notion he acquires from the Spanish educator Tomás Alvira. Through a bibliographical review of Polo's anthropological work, this concept of education is explored in depth. Analyzing the Polian writings, it is concluded that education must be developed from the person, because in this way, each man -unique and unrepeatable-, with the guidance and help of his educators, will be able to fulfill his intimate mission and grow in an unrestricted way in habits of the intelligence and virtues of the will.
\end{abstract}

Keywords: Educational Anthropology, Transcendental Anthropology, Education, Family, Leonardo Polo, Educational Philosophy.

\title{
INTRODUCCIÓN: LA FILOSOFÍA DE LA EDUCACIÓN DESDE LA ANTROPOLOGÍA
}

Todo hombre requiere de la educación para desarrollarse, alcanzar su plenitud, desenvolverse en el mundo como ciudadano y ser un real aporte para la sociedad. Cuando se habla de la esfera social, la educación siempre es un tema fundamental. Año tras año, las familias y los gobiernos de todo el mundo desembolsan grandes cantidades de recursos para educar a las generaciones del futuro. Esto es lógico, ya que de la educación depende el futuro de la sociedad. Por lo mismo, debe estar abierta al fundamento y destino del hombre y no solo abarcar un conjunto de conocimientos, más o menos amplios, que se transmiten a los educandos. Esto es así porque la sociedad está al servicio del hombre, y por esto, «la clave de la vida no es la educación social para servir al colectivo -como en las manadas, hormigueros y colmenas-, sino que la educación en sociedad tiene como fin ayudar a cada uno a crecer como persona» (Polo, 2018a, p. 98).

Por otro lado, si bien existe consenso sobre la relevancia de la educación, es difícil encontrar acuerdos al preguntarse en qué consiste. Si se analizan las definiciones de la Real Academia Española -«crianza, enseñanza y doctrina que se da a los niños y a los jóvenes» (2021) - y la que entrega la Organización de las Naciones Unidas para la Educación, la Ciencia y la Cultura, en el artículo La educación transforma vidas - «la educación es un derecho humano para todos, a lo largo de toda la vida, y que el acceso a la instrucción debe ir acompañado de la calidad» (2021)-, se evidencian diferencias de enfoque y cierto despiste en cuanto al real sentido y al verdadero fin de la educación.

En la primera definición se encuentra un educando pasivo, que «recibe desde fuera» algo que se «da» y parece ser ajeno a él; mientras que en la segunda, se destacan algunas características o consecuencias de la educación, más que un concepto propiamente tal de la misma. Si se continúa ahondando en el tema, al revisar las distintas políticas educativas públicas de los diversos países del mundo, los planes de estudios para formar educadores en las diferentes universidades o los múltiples proyectos educativos de las escuelas y colegios, se 
nota claramente el distinto perfil que se da a la educación en cada una de las entidades que se ocupan, de una u otra forma, de esta importante labor. Entre otras muchas causas, estos enfoques plurales se deben a la diversidad de disciplinas o áreas que estudian la educación: sociología, psicología, evaluación, didáctica, administración y gestión, filosofía de la educación, entre otras.

De las múltiples disciplinas que estudian la educación, la filosofía de la educación es la más relevante. Esto se debe a que la filosofía está en el orden de la verdad, no de lo verosímil o meramente utilitario, y busca fundamentar las distintas realidades en las que se ve inmerso el ser humano. Cuando se inicia una fundamentación de la educación, se evidencia que no es posible fundamentarla desde las ciencias empíricas, puesto que cuando se llega a la pregunta de «para qué», nos encontramos que estas no entregan una solución. Por esto hay que acudir a la filosofía (García Hoz, 1960). De esta manera, si se prescinde de la filosofía de la educación, se puede caer en la fácil creencia de que hoy, con el avance de las ciencias, se sabe mucho más que nunca sobre educación, pero se olvida que se sabe «menos que antes en lo fundamental, en el sentido de la vida y su fin» (Sellés, 2020, p. 167). Por esto no se puede despreciar la filosofía al estudiar la educación, ya que es la que permite alejarse del peligro de que la educación se transforme en una mera técnica o instrucción, ya que no hay que confundirla «con dar y procurar que se practiquen unas reglas de urbanidad; ni tampoco con la sola adquisición de unos conocimientos» (Alvira, 1983, p. 12).

Es por tanto relevante que la educación sea tratada desde la filosofía, puesto que «la teoría y la práctica están muy unidas, porque una mala teoría da lugar a una mala práctica, y a veces las malas prácticas oscurecen la teoría» (Polo, 2017, p.177). La teoría puede iluminar la práctica, para que la educación no sea mera instrucción: «la competencia tiene su lugar en la educación [...] pero no puede tomarse la competencia como base» (Orón, 2018, p. 248). De esta manera, con la filosofía de la educación, se evitará el riesgo de que ocurra una separación entre ética y técnica (Ahedo, 2018). De lo contrario, el quehacer educativo puede transformarse en una mera técnica, y no se trata de eso, sino que «persigue la integridad, hacer buenos hombres y ciudadanos» (Bernal, 1998, p. 33).

En este trabajo se propone que, dentro de las ramas de la filosofía, corresponde estudiar la educación, fundamentándola desde la antropología trascendental, la que estudia el acto de ser personal humano, sujeto de la educación. Esta propuesta responde a que "cómo el hombre se entienda, dependen sus actividades ante la vida y el sentido de su actividad» (Polo, 2016a, p. 102): dentro de ellas, el quehacer educativo. Así, como la filosofía poliana sostiene que la ética -que es un saber práctico- debe fundamentarse en la antropología trascendental, porque el obrar sigue al ser (Polo, 2018b), en la filosofía de la educación debe ocurrir lo mismo, ya que se trata de la educación de cada quién: «la educación, en cuanto perfeccionamiento, implica una modificación en el hombre» (García Hoz, 1962, p. 13), que es el sujeto de la educación. De esta manera, «el saber teórico sobre la condición humana potencia al saber práctico, contribuyendo con su perfeccionamiento» (Arancibia, 2018, p. 123).

En esta misma línea, Víctor García Hoz (1960) afirma que «la idea del hombre y la idea de la vida suministran a la Pedagogía los principios que han de servir de fundamento para explicar racionalmente los problemas educativos previos a aquellos referentes a los medios de actividad educadora» (p. 53). Asimismo, Bernal (1998) sostiene que «sólo se puede comprender un proyecto de educación en un marco que defina qué es el hombre» (p. 369). Como conclusión, debe sostenerse que hay que entender bien a quién se educa para poder fundamentar correctamente la educación, y cada quien es una persona distinta. Así lo resalta Dassoy (2018) al sostener que 
«entender adecuadamente quién es la persona, nos ayuda sobremanera para entender no sólo la educación, sino cómo llevarla a cabo» (p. 214).

García-Viudez (1996) destaca que «sin un sentido trascendental del aprendizaje, el crecimiento personal se detiene y la libertad decae, dejando escapar oportunidades de progreso ético-social» (p. 629). Es por esto que este artículo busca aclarar el concepto de «Educación» desde la Antropología trascendental de Leonardo Polo, un filósofo español de fines del siglo XX que, con notables descubrimientos, amplía los hallazgos de Aristóteles y Tomás de Aquino (Franquet, 1996). Esto se llevará a cabo mediante una revisión bibliográfica a través de las diversas obras donde este pensador expone sus descubrimientos antropológicos.

\section{LA ANTROPOLOGÍA TRASCENDENTAL DE LEONARDO POLO}

Antes de entrar en el concepto poliano de educación se explica, brevemente, en que consiste la Antropología trascendental de Leonardo Polo, la que, siguiendo los hallazgos de Aristóteles y Tomás de Aquino, logra descubrimientos novedosos sobre el hombre, el sujeto de la educación.

Leonardo Polo, al profundizar en el conocimiento intelectual -el ejercido por la inteligencia o razón-, constata que se trata de un conocimiento operativo actual, según el cual, al ejercer un acto o una operación inmanente, este presenta un objeto actualmente conocido. Además, agrega que con este conocimiento objetivo se conoce en presente, por lo que lo describe como presencia mental (Polo, 2016a). Polo (2016a) destaca la limitación de este conocimiento objetivo, sosteniendo que «cuando se piensa lo que se piensa, lo que se piensa ya se ha pensado, lo cual equivale a decir que no puede ser profundizado, o bien que está supuestamente conocido» (p. 126). A esto llama el límite mental (Polo, 2016a). Habiendo identificado este límite mental, la filosofía poliana propone un novedoso método, en el cual se sustenta: el abandono de la presencia mental o el abandono del límite mental; que es la superación de la presencia mental descrita anteriormente. Es un método que, al detectar la presencia mental, avanza más allá de esta, alcanzando un nuevo conocimiento ignorado por el conocimiento objetivo (Polo, 2016a). En palabras de Polo (2016a):

[...] detectar el límite mental permite abandonarlo, es decir, acceder a una temática a la que de otra manera no se llega, pero no por eso es un saber absoluto: es una continuación y una ampliación, pero no el final de la filosofía (p. 145).

De esta forma, el pensamiento poliano distingue entre conocimiento objetivo y conocimiento transobjetivo: el primero conoce objetos por medio de las operaciones, mientras que el segundo se alcanza abandonando la presencia mental con los hábitos, que son actos intelectuales superiores a las operaciones (Polo, 2016b), ya que «mientras que el conocimiento objetivo es inalterable -lo mismo-, la temática accesible al abandonar el límite mental no lo es, sino que exige insistir en ella. En la medida en que se insiste se profundiza» (Polo, 2016a, p. 145). Utilizando este método del abandono del límite mental en su tercera y cuarta dimensión, Leonardo Polo descubre que el hombre está compuesto por tres capas: la naturaleza humana, la esencia del hombre y el acto de ser personal.

La dimensión inferior del hombre está conformada por la naturaleza corpórea humana, el cuerpo biológico (Polo, 2016c), más el alma y sus potencias o facultades en estado natural: inteligencia como tabula rasa y voluntad como potencia pasiva, sin haber sido activadas. Así lo entiende Polo al sostener que «la unidad sustancial alma-cuerpo pertenece al orden de la naturaleza, y es susceptible de elevarse al nivel de la esencia» (Polo, 2016a, p. 164). 
Ascendiendo en su composición, el hombre posee esencia, que es la "perfección de la naturaleza humana, esa autoperfección de la que otros seres vivos corpóreos no son capaces» (Polo, 2015b, p. 146). Se trata de un emerger de la esencia a partir de la naturaleza. Es, por tanto, una dimensión superior a ella, y eso solo puede explicarse por el acto de ser personal humano (Polo, 2015b). Esta progresiva «esencialización» de la naturaleza es guiada o dirigida desde el hábito innato de la sindéresis -equivalente a lo que la psicología moderna describe como yo-: una perfección nativa que depende de la persona y que es el ápice de la esencia del hombre para la filosofía poliana. La sindéresis, para Polo, posee dos dimensiones: el ver-yo, que suscita los actos y hábitos de la inteligencia; y el querer-yo, que constituye los actos y las virtudes de la voluntad. Es importante aclarar que como la sindéresis depende de la persona, sus funciones también dependen de ella; y como el acto de ser personal está conformado por diversas dimensiones (la coexistencia libre, el conocer y el amar personales), el ver-yo depende del conocer personal, mientras que el querer-yo deriva del amar donal personal (2016a). La sindéresis, por tanto, es el hábito innato de la persona que perfecciona la naturaleza y la «esencializa».

Finalmente, en la cúspide del hombre se encuentra el acto de ser personal, que corresponde a su intimidad: la persona. Este acto de ser se distingue del acto de ser de Dios y del acto de ser del universo. Polo (2017) afirma que el acto de ser personal es además, y «a partir de ese carácter de además se puede hablar de intimidad, de persona. Pero no es un término común, sino que persona es cada quien y cada quien es además, es intimidad» (p. 132). En este sentido, «la persona es lo más íntimo, la intimidad misma del hombre. El abrirse de la intimidad implica el aparecer en el mundo lo que no existía de ninguna manera antes en él, pues su origen es la persona» (Polo, 2015a, p. 59). También es importante esclarecer que «el acto de ser personal está conformado por unos trascendentales humanos: la libertad, la intelección como trascendental -es decir, la pura noeticidad del pensar-, y el amor como trascendental» (Polo, 2015b, p. 306). Cabe aclarar que si bien Polo distingue, en un comienzo, cuatro trascendentales personales (coexistencia, libertad, conocer y amar personales), luego los reduce a tres: coexistencia libre, conocer personal y amar donal personal (Sellés, 2021).

De esta manera, el hombre «tiene» cuerpo y alma, pero «es» persona. En este sentido Sellés (2008) sostiene que

El cuerpo y el alma se tienen, pero la persona no se tiene, sino que se es. Como es sabido, al cuerpo pertenecen, entre otras, las funciones vegetativas, los sentidos, los apetitos sensibles. Al alma, en cambio, dos potencias inmateriales: la inteligencia y la voluntad. Por su parte, es característico de la persona la intimidad y la apertura personal a la trascendencia. Esa intimidad abierta es espiritual, es decir, la persona es un espíritu (p. 124)

A modo de resumen, cabe indicar que según la Antropología trascendental poliana, el hombre posee tres dimensiones. Como ya se mencionó, la primera de ellas es la naturaleza del hombre, que responde a su dimensión corporal y a las potencias del alma -inteligencia y voluntad- en estado natural, es decir, como tabula rasa y potencia pasiva, respectivamente. Luego está la esencia del hombre, que está constituida en primer lugar por la sindéresis o el yo -ápice de la esencia-, y por la inteligencia y la voluntad «esencializadas», esto es, una vez que ya han sido suscitados y constituidos sus actos y hábitos por el ver-yo y el querer-yo respectivamente. Y finalmente se encuentra lo más distintivo y propio del hombre que es la persona: el co-acto de ser personal, que es coexistencia libre, conocer personal y amar donal personal.

Es importante agregar que, en la antropología poliana, tanto la esencia como la naturaleza dependen siempre de la persona y que se distinguen necesariamente entre sí, puesto que la esencia es la perfección de la naturaleza (Polo, 2016a, 2015a). Todo esto es encontrado por Leonardo Polo, partiendo desde la distinción real essentia-actus essendi descubierta por 
Tomás de Aquino². Es relevante tener en cuenta esta explicación para poder dar luces a los más variados temas que puedan estudiarse desde la Antropología trascendental: en este trabajo se estudiará el concepto de «educación».

\section{EDUCAR ES «AYUDAR A CRECER»}

Leonardo Polo (2019) sostiene que «educar es ayudar a crecer [...] el hombre es un ser vivo a quien hay que ayudarle a crecer, porque en otro caso, su crecimiento es mucho menor del que es susceptible si se le ofrece esa ayuda» (p. 141). Tras dar esta definición, Polo aclara que la ha obtenido de Tomás Alvira (1983), quien sostiene que «los hijos necesitan ayuda para crecer, para desarrollarse en el más hondo sentido de esta palabra, que se refiere no ya sólo a su aspecto biológico, sino al proceso de perfeccionamiento de la persona humana» (p. 11). Alvira (1983) añade que «el hombre, ese ser que lleva en sí un proyecto al nacer, precisa auxilio, ayuda, con el fin de hacer realidad ese proyecto y lograr que alcance su plenitud, la mayor perfección posible dentro de su condición humana» (p. 11). Por su parte, Leonardo Polo, ahondando en este concepto de educación, afirma que el ser humano se caracteriza porque está hecho para crecer y que jamás deja de hacerlo, ya que el hombre nunca está completamente formado. Agrega también que el hombre no puede crecer solo, ya que necesita de los educadores: sin la educación, el hombre no puede crecer, requiere la ayuda de sus padres, de sus profesores y de la sociedad en general (2018a, 2018b, 2019).

En la misma línea que Polo y Alvira, sostiene García Hoz (1962) que el educador es «un agente externo que pone en movimiento las facultades del alumno y facilita su perfeccionamiento, ordenando los medios exteriores de educación y eliminando los obstáculos que se oponen a la marcha perfectiva del discípulo» (p. 44). En consecuencia, es importante tener presente que el educador asiste o ayuda al educando en su crecimiento y jamás lo reemplaza ni lo sustituye a la fuerza: el que crece y se desarrolla es el educando de manera activa. Asimismo, Altarejos y Naval (2015b) afirman que la educación es la «ayuda al perfeccionamiento humano» (p. 171).

Para Polo «perfeccionamiento» y «crecimiento» tienen el mismo significado (2016b, 2018a, 2018c). De este mismo parecer es Víctor García Hoz, quien sostiene que la educación es una especie de modificación, y que «esta modificación no tendría sentido si no fuera un perfeccionamiento, un cambio hacia la perfección [...] toda educación es una perfección» (1960, p. 17).

Si bien Leonardo Polo dedica una obra entera a plantear aspectos sobre filosofía de la educación, dando incluso una definición de la misma, a través de toda su amplia obra antropológica se puede profundizar en este concepto y sus elementos. Este trabajo pretende comenzar por el concepto de crecimiento humano -con algunas apreciaciones sobre este y sus tipos- para terminar por la necesidad de ser ayudado a crecer.

\section{EL CRECIMIENTO HUMANO}

\section{1. ¿Qué es crecer?}

Para ahondar en la definición de educación de Leonardo Polo, primero debe esclarecerse qué es el crecimiento humano. Para esto es ilustrativo un ejemplo del mismo Polo (2015a)

2 «Ad tertium dicendum, quod cum dicitur: diversum est esse, et quod est, distinguitur actus essendi ab eo cui ille actus convenit. Nomen autem entis ab actu essendi sumitur, non ab eo cui convenit actus essendi, et ideo ratio non sequitur». Tomás de Aquino, De veritate, q. 1 a. 1 ad s.c. 3. 
sobre «un dicho inglés, según el cual, el optimista sostiene que estamos en el mejor de los mundos posibles; el pesimista es el que cree que eso es verdad» (p. 112). Este dicho viene a manifestar que el mundo es mejorable, que se encuentra abierto hacia el futuro, y que está lleno de desafíos. El optimista, para Polo, es aquel que no se satisface con lo que le ha sido dado y, por tanto, vive de una esperanza que se pertenece con una manera de tránsito en el tiempo, que es el «crecimiento, claramente distinto del mero transcurso. Crecer es el modo más intenso de aprovechar el tiempo, es decir, de ponerlo al servicio de la vida. Conviene señalar que el hombre es capaz de un crecimiento irrestricto» (Polo, 2015a, p. 113).

En este sentido hay que sostener que el ser humano, al nacer, no se encuentra acabado por completo, ya que vivir significa crecer, y crecer significa perfeccionarse, lo cual era para los clásicos el destino de la vida. En términos polianos: el crecimiento es la clave de la vida (Polo, 2016b, 2018a, 2018c). De la misma forma, Altarejos y Naval (2015b) afirman que para el ser humano «su nacimiento sólo es la aparición de múltiples posibilidades que irán actualizándose -o no- a lo largo de su existencia» (p. 17); es decir, que cada hombre al nacer no se encuentra acabado, sino que tiene que ir desarrollándose a lo largo de su vida en búsqueda de su plenitud. Para eso hay que ayudarlo: en esto consiste educar.

\section{2. ¿Cómo se crece?}

A lo anterior hay que agregar que el crecimiento del hombre no es independiente de su actuar. De esta manera, cada persona tendrá a su cargo una tarea -un encargo íntimo- a través del que crecerá como hombre. Es decir, la esperanza supone un futuro mejor, siempre y cuando el ser humano se haga mejor y se perfeccione, o sea, en la medida en que cada uno crezca en el cumplimiento de la misión o el encargo recibido. A esto se suma que esta tarea no es posible en soledad, ya que el hombre aislado no posee los recursos necesarios para llegar a un futuro mejor -no puede crecer por su propia cuenta- $y$, por lo tanto, requiere de la ayuda de los demás. Así, el beneficiario de la acción no es solo quien la lleva a cabo, sino que alcanza a los demás: es trascendente (Polo, 2015a).

Es importante destacar que el hombre es un ser vivo que al actuar siempre adquiere un aprendizaje positivo o negativo, es decir, mejora o empeora como hombre. Esto quiere decir que todo ser humano puede crecer o decrecer, pero nunca se mantiene estático. De esta manera cada hombre, al actuar, es beneficiado o perjudicado por su propia actividad, ya que sus actos redundan en crecimiento o decrecimiento de hábitos y virtudes de sus potencias inmateriales: la inteligencia y la voluntad. De acuerdo con este dinamismo, Polo designa al hombre como «perfeccionador perfectible» (2015a, 2015b, 2015c). En este sentido se puede sostener que el hombre es un «plano inclinado» que jamás se mantiene estático, ya que al actuar avanza o retrocede: «si no se crece, la vida retrocede» (García-Viudez, 1996, p. 630).

Dicho de otro modo, en el transcurso de su vida, el hombre puede ir a más o a menos en cuanto hombre, pero jamás se queda como está (Polo, 2015b, 2018b). Así lo esclarece Ahedo (2018) quien, analizando el crecimiento de la voluntad, sostiene que «o se educa la virtud, como crecimiento de la voluntad, o se deja al educando que sucumba ante el vicio. En definitiva, o se educa para desarrollar las capacidades o no se educa y, entonces, las capacidades se envilecen» (p. 107).

Teniendo claro lo anterior, debe agregarse que hay diversas clases de crecimiento. No solo existe el crecimiento corporal -crecer en tamaño o altura-, sino que también se crece en el orden espiritual -se adquieren hábitos intelectuales y virtudes en la voluntad- (Polo, 2018a, 2019). Finalmente, como se verá, también se crece en el acto de ser personal (Polo, 2016a). 


\subsection{Un nacimiento prematuro}

$\mathrm{Al}$ analizar al hombre se nota que es un animal que nace muy prematuramente y que, por lo tanto, necesita de un cuidado particular después de su nacimiento. Cualquier niño recién nacido es completamente indefenso y depende totalmente de otros -en principio, de sus padres- para sobrevivir: un niño no se puede alimentar, no se puede vestir, ni se puede asear autónomamente, necesita asistencia para casi todo (Polo, 2019). Esto quiere decir que el hombre nace débil y, como consecuencia, requiere de un tipo de crecimiento muy particular. Así, Polo (2019) sostiene que este crecimiento es una estrategia generativa que consiste en «una nidificación a ultranza, una nidificación que también es aprovechada por la naturaleza humana para la educación. Al hombre no le basta una maduración biológica; necesita educación» (p. 150).

Esto indica que, en el hombre, la educación es fundamental, y que la tarea de los padres no se limita solo a la procreación, a la alimentación y al cuidado material, sino que además deben proveer la educación. Así, al ser humano no le basta la embriogénesis, sino que sigue creciendo tras su nacimiento, y en este crecimiento «ha de intervenir el propio sujeto aprendiendo. Por consiguiente, ese ayudar a crecer, que es la educación, no versa sobre el crecimiento orgánico, sino que se refiere al crecimiento posterior a aquél en que interviene ya el espíritu» (Polo, 2019, p. 155).

\section{TIPOS DE CRECIMIENTO}

\subsection{El crecimiento orgánico}

Todos los seres vivos, al poseer vida vegetativa, tienen crecimiento orgánico, que consiste en la función nutritiva, en la operación de crecer y en la función generativa que es la procreación, es decir, la capacidad de reproducirse. Estas tres funciones están ordenadas jerárquicamente, desde la nutrición a la reproducción (Polo, 2015e). Siguiendo este descubrimiento aristotélico, Polo sostiene que el primer tipo de crecimiento en el hombre es el común a los organismos pluricelulares, lo que se denomina embriogénesis. Esta clase de crecimiento se da con el código genético de cada ser humano, que es una estructura que se desarrolla. Asimismo, afirma que son más perfectas aquellas naturalezas cuyo crecimiento no se limita simplemente a la reproducción, sino que tienen su propio fin y culminación, no limitándose al servicio de la especie. El crecimiento contiene el significado de la reproducción, pero además agrega la diferenciación celular (2015d).

Sin perjuicio de lo anterior, este crecimiento orgánico no es el más característico del ser humano, ya que el hombre es capaz de crecer todavía más (Polo, 2018a). El hombre tiene la capacidad de crecer más allá de su constitución genética, ya que puede crecer en el sistema nervioso, en las conexiones neuronales. Este tipo de crecimiento no culmina con la embriogénesis y va más allá, pero sigue siendo un crecimiento finito, que al tener que ver con el conocimiento, no es simplemente un crecimiento orgánico -sino algo más-, pero que sigue teniendo límites (Polo, 2015b). Esta fase de crecimiento se

\footnotetext{
caracteriza por el perfeccionamiento del cerebro, y en ella aparece, finalmente, el hombre, que, ante todo, puede caracterizarse como animal inventor, es decir, que usa su cerebro para actividades que no tienen como fin la mera alimentación, sino la construcción de artefactos. En este sentido se suele hablar de imaginación creadora. El crecimiento cerebral en el hombre, lleva consigo normalmente un fuerte desarrollo de los llamados sentidos internos: imaginación, memoria y estimativa (Polo, 2015a, p. 107).
} 
Sin embargo, el hombre es capaz de un crecimiento superior al crecimiento orgánico. Esta clase de crecimiento -que es de carácter irrestricto- es el espiritual, que consiste en la perfección de las facultades del alma, por medio de la adquisición de hábitos en la inteligencia y de virtudes en la voluntad, que se desarrollan a lo largo de toda la vida del hombre, sin límite alguno (Polo, 2017, 2019).

\subsection{El crecimiento irrestricto de las facultades del alma}

A este crecimiento espiritual, Leonardo Polo lo denomina «esencialización», por ser el paso de la naturaleza a la esencia. El hombre crece como esencia -esencializa su naturaleza-, y ese crecimiento consiste en la adquisición de hábitos que perfeccionan la inteligencia y virtudes que perfeccionan la voluntad (2015b, 2016c). Esto, al ser distintivo del hombre -lo diferencia esencialmente del universo material, ya que el universo no se perfecciona según su propio actuar libre, sino con la unidad de orden-, es a lo que se le puede llamar propiamente crecimiento humano, pues mediante este crecimiento, el hombre se hace más humano.

Este es el sentido de la vida: perfeccionarse como hombre, alcanzar perfección, plenitud humana (Polo, 2015b, 2016c, 2017). De la misma manera, García Hoz (1962) afirma que «la causa de la educación está en la posibilidad de perfección que el hombre tiene» (p. 18). Así, esta "perfección que se busca en la educación es de lo específicamente humano» (García, 2019, p. 342).

Este crecimiento o esencialización, tiene una doble dimensión: el crecimiento de la inteligencia y el crecimiento de la voluntad, y se realiza desde el hábito innato de la sindéresis, el cual también posee una doble vertiente: suscita los actos y hábitos de la inteligencia a través de ver-yo; y constituye los actos y las virtudes de la voluntad por medio de querer-yo (Polo, 2016a, 2015a). Esencia, por lo tanto, expresa perfección, ya que las virtudes y «los hábitos modifican la naturaleza» (García, 2019, p. 367), perfeccionándola. Por eso se puede decir que «la esencia del hombre no es un dato, sino un cometido de la libertad que dura toda la vida, a saber: la conquista creciente de la dependencia de lo humano respecto del ser personal» (Polo, 2018b, p. 200). Con otras palabras, «el sentido de la vida humana está justamente en manifestar cada vez mejor a la persona; porque a través de su esencia, el ser humano se puede manifestar» (Polo, 2015b, p. 316). Entendido de esta manera, se puede afirmar que «la persona es intimidad y desde ella se expresa. Porque estrictamente hablando, con la educación no se forma a nadie, sino que se ayuda para que el alumno se forme a sí mismo» (Orón, 2018, p. 251). Este podría ser uno de los fines de la educación: lograr que la persona de cada educando se manifieste en su esencia, perfeccionando así su naturaleza.

También sostiene Polo que el crecimiento humano depende del mismo hombre que crece, el cual siempre puede ser más humano - puede crecer más-, sin importar la edad o condición, ya que no tiene límite alguno. Nunca se es todo lo hombre que se puede llegar a ser, siempre se puede ser más humano, siempre cabe perfeccionarse. Este sentido de perfeccionamiento es ético, y por esto la ética es inseparable del crecimiento del hombre (Polo, 2016c, 2017). Así, respecto del crecimiento espiritual, se puede afirmar que el hombre está hecho para perfeccionarse, en el sentido de que la persona premia su esencia: eso es la esencialización. Pero el hombre también puede perfeccionar el universo. Por eso se le denomina como «perfeccionador perfectible». Perfeccionador, puesto que su relación con el universo es perfectiva; y perfectible, porque esa perfeccionabilidad es la «esencialización», es decir, la adquisición de hábitos de la inteligencia y virtudes de la voluntad (Polo, 2015b).

Cabe destacar que este crecimiento de la esencia humana depende de la persona: «el hombre es un proceso de personalización y, por lo tanto, de trascendentalización, porque la persona es por donde el hombre se trasciende a sí mismo» (Polo, 2015d, p. 32). De esta manera, el 
crecimiento del alma humana se realiza desde la persona, es decir, desde su acto de ser personal -su intimidad-, de la que depende la sindéresis. Esto es lo mismo que decir que, desde la persona -a través del hábito innato de la sindéresis-, el hombre esencializa su naturaleza. Por lo mismo la Antropología trascendental poliana sostiene que la esencia es la manifestación de la persona (Polo, 2016a). En este sentido, Leonardo Polo (2015b) afirma que

en la esencia humana, los hábitos son la autoperfección de la naturaleza. No son una causa distinta de la naturaleza que ordena, sino una perfección que la naturaleza se da a sí misma, naturalmente por la persona, que es el acto de ser humano, que es la que tiene que establecer la diferencia con la esencia y, por lo tanto, los hábitos dependen de la persona. Los hábitos serían imposibles si no fuera por ella (p. 159).

En la misma línea, Ahedo (2018), siguiendo a Leonardo Polo, afirma que «el carácter perfectivo del hábito, indica que es un crecer libre que depende de la persona de modo que, si la persona no quiere disponer del crecimiento de la virtud, no mejora como persona» (p. 100). Así, la educación «que se realiza en el nivel esencial, ha de tener esto en cuenta: que lo que se da en la esencia humana deriva de la persona humana» (Izaguirre y Moros, 2007, p. 119).

\subsection{El crecimiento de la persona}

Los hábitos y virtudes son el perfeccionamiento de la naturaleza, pero no es el fin del ser humano, ya que este crecimiento es un medio para la persona, porque está al servicio del amor (Ahedo, 2018). Por tanto, sin perjuicio de que el crecimiento del alma -y de sus facultades de inteligencia y voluntad- es irrestricto, todavía existe un crecimiento mayor que el de la adquisición de hábitos intelectuales y virtudes de la voluntad en el hombre, que es el crecimiento irrestricto de la persona: «el crecimiento personal es la tercera y más alta modalidad de la vida creciente en el hombre» (Vargas, 2019, p. 153). Este es el mayor crecimiento que se da en el ser humano, el crecimiento de su acto de ser personal, que consiste en aumentar cada vez más la capacidad de aceptar y, consecuentemente, de darse (Polo, 2016a, 2015a).

Por tanto, este crecimiento corresponde a la donación sin medida. Así lo afirma Ahedo (2018), señalando que hay que entender las relaciones interpersonales como «una optimización de la persona porque se mejora como persona cuando, al coexistir con otras personas, cada uno realiza lo que es propio del ser humano, darse» (p. 100). Y de esta manera el acto de ser personal crece libremente sin límites, ya que este «crecimiento personal, en tanto que donal, no se detiene sino libremente, por el decaer de la libertad humana» (Vargas, 2019, p. 163).

Esta donación tiene relación directa con la misión encomendada a cada quién en su intimidad (Polo, 2016a). De esta manera, la educación de la persona consiste en ayudar a «conocer íntimamente en cierta medida el ser que tanto uno como los demás estamos llamados a ser (vocación) y responder personalmente en consecuencia, y ayudar a responder a los demás» (Sellés, 2013, p. 88). Así, cada educando «está llamado a algo único; cada persona tiene una tarea encomendada distinta para cada quién, cada uno de nosotros tenemos un proyecto personal. Cada persona humana es un don para los demás, llamado a destinarse» (Dassoy, 2018, p. 221). De esta forma, «la educación personal nace del amor personal, manifiesta el amor personal y se encamina al amor personal. De manera que, si se desvincula la educación del amor personal, ésta carece de sentido personal» (Sellés, 2013, p. 77). Por esto el educador que «no acepta a cada una de las personas a quienes educa como quienes son-distintas-, en rigor no educa personalmente. A su vez, sólo tiene sentido educar si se es aceptado como una persona distinta e irrepetible» (Sellés, 2013, p. 97).

Esta capacidad de crecer en la donación es exclusiva de la intimidad del hombre, puesto que solo el ser con intimidad posee capacidad de dar -de darse- sin perder (Polo, 2015d, 
2018a): porque la actividad propia de cada quién consiste en «dar-se, dar el don que co-existencialmente se es; antes que el dar-se está el aceptar-se como don» (Vargas, 2019, p. 163). Dicho de otra manera, «damos en la medida en que aceptamos, y nuestras obras valen en la medida en que son aceptadas y ofrecidas» (Rodríguez y Vargas, 2013, p. 57). Por esto, afirma Polo (2018a) que hablar de intimidad es hablar de donación personal: «la persona es el ser capaz de crecer sin límites, puesto que da sin perder; aporta, es una intimidad no cerrada» (p. 335). Esto está profundamente unido a la tarea encomendada a cada quien, a la tarea o encargo que cada persona recibe en su intimidad (Polo, 2016a). En consecuencia, «la educación no viene a satisfacer una necesidad, sino a hacer posible esta llamada interior, por ello el ser humano necesita formación» (Orón, 2018, p. 247).

\section{LA NECESIDAD DE SER AYUDADO EN EL CRECIMIENTO}

Para finalizar el análisis de la definición de educación que ofrece Leonardo Polo, es pertinente atender a la necesidad de recibir ayuda para crecer. Lo primero que debe establecerse en este sentido es que el único que es capaz de crecer es cada hombre, pues nadie puede crecer por él: depende de cada uno el seguir creciendo, el formarse y alcanzar el estado más perfecto de hombre. En esta misma línea, García Hoz sostiene que el que crece es cada uno, y no es simplemente algo que viene de afuera (1960). Polo sostiene que incluso conviene que el hombre nazca incompleto, para que se pueda modelar él mismo de manera creciente. Esto ocurre con ayuda de la educación, la que comienza luego del nacimiento de cada hombre (2019).

Sin perjuicio de lo anterior, aunque el crecimiento dependa en último término de cada uno, el hombre debe recibir ayuda para crecer: en eso consiste la educación. En este sentido, afirma Polo (2015d) que si bien

el crecimiento es de incumbencia de cada uno, de modo que en este punto nadie puede sustituir a otro, lo que sí es posible y, a la vez, requerido, es ayudar a crecer. Ayudar a crecer no es sólo arreglo o progreso, sino una asistencia, una aportación que el que crece paga sobradamente: nada menos que creciendo. Lo más grandioso que en este mundo cabe encontrar es un vivir humano en crecimiento. El rendimiento de la ayuda a crecer es incomparablemente mayor que cualquier inversión en el proceso progresivo del capital (p. 58).

Así, hay que establecer que el hombre es constitutivamente creciente y necesita de una ayuda para lograrlo. De esta manera, si bien el crecimiento depende de cada uno, se requiere de una asistencia, de una ayuda, para alcanzar ese crecimiento (Polo, 2015d), ya que el hombre, al no poder crecer autónomamente «tiene que ser educado por personas. Sin educación, el hombre no crece. Esto es evidente. El hombre es un ser eminentemente social porque no es independiente en su crecimiento del contacto educador de otras personas» (Polo, 2018a, p. 98).

Esta misma conclusión se puede extraer si se tiene en cuenta el significado etimológico de la palabra educación - procedente de educere-, que significa ""extraer" o "sacar", según el cual, la educación sería la acción de sacar algo del hombre» (García Hoz, 1960, p. 15). Sin embargo, quien educa jamás suplanta al educando, solo lo ayuda, de manera que la tarea «del educador es asistencial, no es constitutiva de los hábitos: ni de los intelectuales, ni de las virtudes. Por eso no puede realizarse sino a través de un respeto exquisito a la libertad del que se está educando» (Izaguirre y Moros, 2007, p. 122). 
Esta ayuda en la educación se logra a través de las interrelaciones personales (Orón, 2018), ya que «ayudar a otras personas a crecer consiste en dar, lo que implica la necesidad de aceptar al otro como quien es, no simplemente en función de lo que es» (Ahedo, 2018, p. 103). «Pero este asunto es difícil, porque una persona no es un qué sino un quién y, obviamente, nos resulta más fácil conocer un qué que un quién» (Sellés, 2008, p. 125). En concreto, esto se logra desde la orientación educativa (García Hoz, 1985). Así, Polo (2019) afirma que «al niño hay que proporcionarle esta orientación básica» (p. 304) y que «sin orientación, la educación no es concebible, pues se educa para. Pero precisamente por ello, educar no es limitarse a transmitir [...]. El educador acierta si ayuda a que las energías del alumno se pongan en marcha» (Polo, 2015d, p. 79). De la misma forma, para García Hoz (1960), «la orientación personal es el proceso de ayuda a un sujeto para que llegue al suficiente conocimiento de sí mismo y del mundo en torno que le haga capaz de resolver los problemas de su vida» (p. 200). Así, «para "personificar" hay que orientar, hay que influir, en una palabra: educar» (Polo, 2015d, p. 79). Para lograr esto es fundamental la virtud de la amistad (Bernal, 1998; García Hoz, 1960, 1985; Pieper, 2017; Polo, 2016a), la cual podrá ser objeto de otra investigación, porque desviaría mucho del tema de este trabajo.

De esta manera, «educar es dar al hombre una cierta suficiencia, que el hombre se valga por sí mismo» (Polo, 2018c, p. 38).

Con otras palabras, la educación es un proceso donde el sujeto va alcanzando paulatinamente la capacidad para guiar su propia vida (García Hoz, 1960). Sin embargo, hay que tener presente que este valerse por sí mismo o guiar su propia vida no significa dejar de crecer, sino crecer de manera más acorde con el ser personal que es -necesitando menos ayuda ajena, aunque siempre se necesitará de ella-, puesto que el hombre siempre puede crecer, debido a que su crecimiento es irrestricto, no tiene límites (Polo, 2018a). Esa asistencia es recibida de parte de los educadores: padres, profesores y sociedad. Principalmente de los padres, cuya labor no se limita solo a la procreación y crianza de los hijos, sino que también a su educación (Dassoy, 2018; García, 2019; García Hoz, 1960, 1962, 1985; Polo, 2019).

\section{CONCLUSIONES}

En este estudio sobre el fundamento de la educación según Leonardo Polo, y tras revisar sus obras junto a otros trabajos de investigación sobre ellas, se puede concluir:

1. Todo hombre está diseñado para crecer, y este crecimiento no es solo de carácter corporal, sino que también es espiritual. El crecimiento espiritual -que consiste en el crecimiento de la esencia del hombre y el crecimiento del acto de ser personal- es superior al corporal, ya que es más característico, propio y distintivo del hombre. Además, es un crecimiento irrestricto, no como el corporal, que tiene límites. Cuando se crece corporalmente se llega a un punto donde no se puede crecer más, o incluso se decrece; en cambio, el crecimiento espiritual no tiene límite alguno, siempre se puede seguir creciendo en hábitos de la inteligencia, en virtudes de la voluntad y en la elevación del acto de ser personal.

2. La educación, si bien tiene que ocuparse de la dimensión corporal del ser humano, sobre todo debe dedicar tiempo, energías y recursos al crecimiento espiritual, es decir, a la adquisición de hábitos intelectuales y virtudes de la voluntad, y en crecer como el ser que se es y se está llamado a ser. Esto no quiere decir que el crecimiento corporal sea irrelevante o deba descuidarse, sino que simplemente se resalta y se eleva el crecimiento espiritual -que es superior-, ya que es el más distintivo y característico del hombre y, por tanto, es el crecimiento propiamente humano. 
3. El ser humano crece siempre, se perfecciona espiritualmente mediante la «esencialización» de su naturaleza. Esta esencialización se da a través de la sindéresis, un hábito innato que depende de la persona. A través de la sindéresis, actuando desde el ver-yo, se suscitan actos y hábitos en la inteligencia; y actuando desde el querer-yo, se constituyen actos y virtudes en la voluntad. Por tanto, se puede afirmar que la educación es la personalización de cada ser humano por medio de la sindéresis.

4. La esencialización, al provenir de la persona -ya que es manifestación suya-, es única e irrepetible para cada hombre y responde a su intimidad. No existen dos personas iguales, por lo que no hay dos crecimientos, desde la persona, que sean iguales. Cada ser humano es único e irrepetible. Esto es muy relevante, ya que lo que generalmente se entiende como educación integral, se mueve solo en el ámbito de la ética, en la que se establece un «modelo ideal»-formado por un conjunto de virtudes- a seguir, donde hay que replicar este modelo en todos los educandos por igual. Sin embargo, cabe recordar que la ética es segunda respecto de la antropología de la intimidad: el obrar sigue al ser, nunca al revés. Por esto se hace necesaria una educación personalizada, centrada en cada quién.

5. En la educación personalizada, la labor del educador consiste sobre todo en orientar al educando. Cada uno crece y se perfecciona a su manera, con sus ritmos, de forma única e irrepetible según su acto de ser personal, según su intimidad. Por esto, los educadores no pueden intentar suplantar al educando, «enseñándole» ciertas cosas para que se perfeccione; sino que la función de los educadores es facilitar al educando las condiciones para que él mismo, desde su acto de ser personal -único e irrepetible-, pueda crecer cada vez más y llegar a ser la persona que está llamada a ser.

6. Para lograr la orientación en el ámbito educativo es fundamental la virtud de la amistad, ampliamente tratada desde los descubrimientos aristotélicos, por Leonardo Polo. Se considera necesario ahondar en esta virtud y en su rol para la educación en investigaciones futuras.

7. Parece conveniente proseguir investigando en este intento de fundamentar la educación desde la Antropología trascendental de Leonardo Polo, ya que con sus hallazgos se amplían notablemente los descubrimientos aristotélicos y tomistas, proporcionando mayor profundidad a esta tarea humana y al hombre, sujeto de la educación. Así se podrá ahondar en la fundamentación de la filosofía de la educación.

\section{REFERENCIAS}

Ahedo Ruiz, J. (2018). Las relaciones interpersonales como clave para la educación de la virtud en la familia. Studia Poliana: Primero familia, segundo educación, 20. https:// doi.org/g7np

Altarejos, F. y Naval, C. (2015b). Filosofía de la educación (3ª ed.). Eunsa.

Alvira, T. (1983). ¿Cómo ayudar a nuestros hijos? Ediciones Palabra.

Arancibia, M. D. (2018). Notas acerca de la noción de educación según la antropología trascendental. Studia Poliana: Primero familia, segundo educación, 20, 121-157. https://doi.org/g7nq 
Bernal Martínez de Soria, A. (1998). Educación del Carácter / Educación Moral, Propuestas Educativas de Aristóteles y Rousseau. EUNSA.

Dassoy, M. (2018). La familia, primer ámbito de la educación personalizada. Studia Poliana: Primero familia, segundo educación, 20, 213-223. https: / / doi.org/g7nr

Franquet, M. J. (1996). Trayectoria intelectual de Leonardo Polo. Anuario filosófico, 29, 303322.

García, J. A. (Ed.). (2019). Sobre la filosofía de Leonardo Polo: Familia, Educación y Economía. Ideas y Libros Ediciones.

García Hoz, V. (1960). Principios de pedagogía sistémica (3ª ed. renovada). Ediciones Rialp.

García Hoz, V. (1962). Cuestiones de filosofía individual y social de la educación (2a ed.). Ediciones Rialp.

García Hoz, V. (1985). Educación Personalizada, (6 ed.), Madrid, Rialp.

García-Viudez, M. (1996). Aportaciones de Leonardo Polo para una teoría antropológica del aprendizaje. Anuario Filosófico, 29, 627-649.

Izaguirre, J. M. y Moros, E. R. (2007). La tarea del educador: la sindéresis. Studia Poliana, $9,103-127$.

Organización de las Naciones Unidas para la Educación, la Ciencia y la Cultura. (14 de junio de 2021). La educación transforma vidas. https: / / es.unesco.org/themes/education.

Orón Semper, J. V. (2018). Educación centrada en el crecimiento de la relación interpersonal. Studia Poliana: Primero familia, segundo educación, 20, 241-262. https:// doi.org/g7ns

Pieper, J. (2017). Las virtudes fundamentales (11 ${ }^{\mathrm{a}} \mathrm{ed}$.). Ediciones Rialp.

Polo, L. (2015a) Epistemología, creación y divinidad. En Obras Completas, Serie A, vol. XXVII. Eunsa.

Polo, L. (2015b). La esencia del hombre. En Obras Completas, Serie A, vol. XXIII. Eunsa.

Polo, L. (2015c). La originalidad de la concepción cristiana de la existencia. En Obras Completas, Serie A, vol. XIII. Eunsa.

Polo, L. (2015d). La persona humana y su crecimiento. En Obras Completas, Serie A, vol. XIII. Eunsa.

Polo, L. (2015e). Lecciones de psicología clásica. En Obras Completas, Serie A, vol. XXII. Eunsa.

Polo, L. (2016a). Antropología trascendental. En Obras Completas, Serie A, vol. XV. Eunsa.

Polo, L. (2016b). Presente y futuro del hombre. En Obras Completas, Serie A, vol. X. Eunsa.

Polo, L. (2016c). Quién es el hombre. Un espíritu en el tiempo. En Obras Completas, Serie A, vol. X. Eunsa.

Polo, L. (2017). Persona y libertad. En Obras Completas, Serie A, vol. XIX. Eunsa. 
Polo, L. (2018a). Escritos menores (2001-2014). En Obras Completas, Serie A, vol. XXVI. Eunsa.

Polo, L. (2018b). Ética: hacia una versión moderna de los temas clásicos. En Obras Completas, Serie A, vol. XI. Eunsa.

Polo, L. (2018c). Lecciones de ética. En Obras Completas, Serie A, vol. XI. Eunsa.

Polo, L. (2019). Ayudar a crecer. Cuestiones de filosofía de la educación. En Obras Completas, Serie A, vol. XVIII. Eunsa.

Real Academia Española: Diccionario de la lengua española, 23. ${ }^{a}$ ed., [versión 23.4 en línea]. https:// dle.rae.es [14 de junio de 2021].

Rodríguez, A. y Vargas, A. I. (2013). La familia a la luz del carácter personal. Estudios sobre educación, 25, 49-67.

Sellés, J. F. (2008). Profesor de personas. Las dificultades educativas «radicales» y una propuesta de solución. Estudios sobre educación, 15, 139-157.

Sellés, J. F. (2013). Los tres agentes del cambio en la sociedad civil: Familia, Universidad y Empresa. Eiunsa.

Sellés, J. F. (2020). 33 virtudes humanas según Leonardo Polo. Eunsa.

Sellés, J. F. (2021). Teoría de la voluntad. Cómo disipar su oscuridad según Leonardo Polo. Eunsa.

Vargas, A. I. (2019). El crecimiento del ser personal. Studia Poliana: Las dimensiones del abandono del limite mental, 21, 141-170. https:// doi.org/g7nt 